\title{
O IDOSO NA CONTEMPORANEIDADE: A NECESSIDADE DE SE EDUCAR A SOCIEDADE PARA AS EXIGÊNCIAS DESSE "NOVO" ATOR SOCIAL, TITULAR DE DIREITOS
}

\author{
Dulce Consuelo Andreatta Whitaker
}

RESUMO: Este artigo descreve o quadro de transformaçôes históricas do Brasil, na segunda metade do século Xx, para inserir aí a questão do idoso, numa perspectiva do envelhecimento da população. Situa as mudanças sociais, a perda de poder do idoso, fruto da urbanização e da modernização, com sua estrutura de empregos que transformou o antigo chefe da família extensa no aposentado. Propõe então medidas para recuperação da dignidade dessa importante "categoria sociológica", a partir da educação da nova sociedade. Sugere ainda que, para os professores de crianças e adolescentes que receiam lidar com o Estatuto da Criança e do Adolescente, talvez um bom caminho para enfrentar a complexa área dos direitos humanos seja trabalhar com seus alunos na valorização da memória do idoso, o que significa ao mesmo tempo fazê-los adquirir conhecimentos e valorizar os mais velhos, reconhecendo-os como titulares de direitos.

Palavras-chave: Envelhecimento da população. Mudança social. Dignidade do idoso. A escola e a memória do idoso.

THE ELDERLY IN CONTEMPORANEOUSNESS:

THE NEED TO EDUCATE SOCIETY TO THE DEMANDS OF THESE "NEW" SOCIAL ACTORS WHO OWN RIGHTS

ABSTRACT: This paper explores the historical framework of social changes, in the second half of the $20^{\text {th }}$ century, in Brazil. It highlights the issue of the elderly within an ageing population. It then

Doutora em Sociologia e professora-colaboradora do Programa de Pós-Graduação em Educação Escolar da Universidade Estadual Paulista (unEsP, campus de Araraquara). E-mail: silonofre@uol.com.br 
O idoso na contemporaneidade: a necessidade de se educar a sociedade...

locates social changes as the power loss of the elderly, due to the urbanization and modernization whose new job structure has transformed ex-heads of extended families into retired people. Next, it proposes measures to rescue the dignity of this important "sociological category", based on the education of the new society. It suggests that, for teachers who do not dare to deal with the Children and Adolescent Statute (CAS), a good path to confront the complex area of Human Rights could be working with their students to value the elderly memories. This thus means that children and teenagers should get knowledge and value the elderly, acknowledging them as rights owners.

Key words: Ageing population. Social changes. Elderly dignity. School and elderly memories.

\section{Introdução}

Art. $3^{\circ}$ - É obrigação da família, da comunidade, da sociedade e do Poder Público assegurar ao idoso, com absoluta prioridade, a efetivação do direito à vida, à saúde, à alimentação, à educação, à cultura, ao esporte, ao lazer, ao trabalho, à cidadania, à liberdade, à dignidade, ao respeito e à convivência familiar e comunitária. (Lei n. 10.741 , de $1^{\circ}$ de outubro de 2003; Brasil, 2003, p. 1)

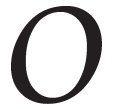

Estatuto do Idoso, aprovado em 2003, traz um novo e compreensivo olhar em relação ao idoso, o qual passa a ser visto como sujeito de direitos (ou, pelo menos, deveria ser visto como tal).

Acontece que uma gama de preconceitos rodeia o envelhecimento em nosso país (Whitaker, 2007) e a sociedade precisa ser educada para compreender o envelhecimento sobre esse novo prisma. Está na hora de repensar as atitudes que infantilizam o idoso e o assistencialismo, que, principalmente nas camadas exploradas, trata-o como indigente, transformando em esmola, ou favor, as poucas políticas públicas que amenizam essa fase da existência, em relação às quais se configuram direitos humanos estabelecidos como direitos sociais em diplomas legais (Lei n. 10.741/2003). Este artigo é um ensaio que pensa a escola como locus privilegiado para o início de um novo tempo, em que a dignidade dos idosos seja um marco fundamental. 


\section{O país jovem que vai envelhecendo}

Durante décadas, ensinava-se em aulas de Geografia Humana que o Brasil era um país jovem. Entre altas taxas de natalidade e de mortalidade, configuravam-se pirâmides demográficas quase perfeitas na forma, através das quais se recebia apenas instrução - um conhecimento importante para compreensão dos indicadores que caracterizavam o país.

Não havia, nessas aulas de Geografia, qualquer mensagem negativa em relação aos idosos, ao contrário, lamentavelmente esses indicadores, ao lado dos índices de analfabetismo e da incidência de doenças tropicais, colocavam o Brasil entre os países subdesenvolvidos. Afinal, essas taxas de mortalidade levavam muito cedo os avós e deixavam, em muitas famílias, marcas profundas de perdas de filhos pequenos, vitimados por difteria, poliomielite ou, simplesmente, por desidratação. Mas estes não eram conteúdos para o currículo escolar.

A escola permanecia distante dos problemas sociais e os idosos ou seja, aqueles que sobreviviam a tantas mazelas - eram percentualmente poucos e contavam com a família extensa para tudo o que necessitassem (Whitaker, 2007).

Mudanças profundas afetaram essas configurações sócio-históricas. A queda nas taxas, tanto de mortalidade quanto de natalidade, alterou aquela pirâmide demográfica, que, aos poucos, foi perdendo sua forma piramidal, e fez surgir maior expectativa de longevidade para toda a população brasileira.

Assim, a esperança de vida, que girava em torno de 60 anos, nos anos 80 do século passado, ultrapassou os 70 anos, já nos anos 2000, e a população acima de 65 anos mais que dobrou sua participação no total da população brasileira na segunda metade do século XX - passando de 2,4\% em 1990 para 5,8\% em 2001 - com projeções para $15 \%$ em 2020 (CNBB, 2002).

Não são necessários mais dados para sentir a força da longevidade atuando no conjunto da população. O importante é lembrar que esse envelhecimento da população ocorre num quadro de mudanças sociais aceleradas, cujas circunstâncias transformam, muitas vezes, a vida do idoso em sofrimento e privação. 
O idoso na contemporaneidade: a necessidade de se educar a sociedade...

Não basta o Estatuto do Idoso. Embora seja uma grande conquista, é pouco conhecido e o estabelecimento dos direitos sociais dessa "crescente" categoria sociológica exige mudanças profundas nas atitudes da população, face ao seu envelhecimento.

$\mathrm{O}$ argumento principal deste artigo é de que a escola deve ser chamada a colaborar na compreensão deste "novo" ator social. Diferentemente do passado, quando apenas mencionava-se o "país jovem", sem qualquer juízo de valor, os gestores da Previdência, muitos economistas e a mídia se empenham hoje em "acusar" os idosos pelas crises da Previdência e proclamar que os adultos em idade produtiva precisam trabalhar muito para sustentar o grande percentual de velhos que não cessa de crescer. Esquecem esses tecnocratas que os idosos de hoje trabalharam no passado - quando se começava a trabalhar já na infância - e sustentaram os adultos que estão hoje em "idade produtiva”. Esquecem, ou fingem esquecer, pois, na realidade, são porta-vozes de um sistema econômico que sacrifica os grupos vulneráveis para garantir o superávit primário, que alimenta os lucros das bolsas de valores ao redor do planeta. Com seus discursos economicistas, escondem ainda o fato de que, no passado, a grande maioria desses idosos contribuiu com parte substancial dos seus ganhos para ter direito às aposentadorias que hoje são apresentadas ao grande público como privilégios ou, o que é pior, assistencialismo.

Cabe agora aos professores, e não só nas aulas de Geografia $\mathrm{Hu}$ mana, desvelar para os adolescentes as artimanhas ideológicas que encobrem os desmandos no INSS e na Previdência, colocando nos idosos a culpa pelo seu déficit permanente. Vejamos, primeiramente, a questão histórico-social do envelhecimento da população e as transformações que acompanham este processo.

\section{O que mudou na posição do idoso na contemporaneidade}

Em Whitaker (2007), explica-se longamente como a industrialização e a urbanização do país alteraram substancialmente a posição do idoso dentro da família e na sociedade como um todo. Até os anos 60 do século passado, o Brasil era um país agrário e, como tal, abrigava a maior parte da sua população no campo. Não caberia aqui, no curto espaço de um artigo, descrever o formidável impacto sobre a 
população que resultou da industrialização e da modernização do país. O processo está mencionando em Whitaker (op. cit.) e detalha-se ali, sociologicamente, a mudança na posição do idoso relacionada: a todas as transformações na estrutura de empregos; à entrada da mulher no mercado de trabalho; ao êxodo rural; ao crescimento das cidades e, principalmente, à substituição da família ampliada pela família conjugal moderna.

Assim, o estilhaçamento dos clãs e a modernidade da família conjugal repousam no desaparecimento do território familiar, do qual derivava o poder do idoso. $\mathrm{Na}$ zona rural, o idoso era o fazendeiro, o sitiante ou o responsável por um lote. Na cidade, era o dono de um grande ou pequeno negócio, concretamente situado. Em todos os casos possíveis dessa caleidoscópica conformação do espaço, o poder estava nas mãos do proprietário (em geral, idoso) que abrigava filhos, filhas, genros e noras, que só chegariam ao "poder" quando os mais velhos morressem. E, então, já estariam eles também sendo considerados idosos. Esse poder, baseado na posse do negócio, da fazenda ou do lote, criava o modelo de respeito e veneração que, obviamente, se estendia a todas as classes sociais.

Hoje, o idoso é, com maior probabilidade, um aposentado. $\mathrm{O}$ avanço das grandes corporaçóes multinacionais e a vitória das modernas plantations acabaram com o poder pessoal ligado à pequena empresa e as famílias extensas se pulverizaram pela ação da estrutura de empregos que separou o local de trabalho do local de moradia. ${ }^{1}$

Em síntese, os idosos não podem mais contar com o apoio da extensa parentela que lhes garantia apoio e bem-estar. Hoje, os idosos devem resolver a maior parte dos seus problemas sozinhos, devem frequentar grupos de terceira idade e ler livros de autoajuda, porque a depressão é ameaça constante, face às doenças que os ameaçam durante o envelhecimento. E aqui chego a um ponto crucial. É difícil escapar à depressão, quando, aos achaques próprios do envelhecimento, associam-se: o discurso dos gestores da Previdência sobre o peso das pensóes e aposentadorias; a ideologia perversa de que os idosos não precisam receber o montante que recebiam quando em idade ativa; e os apelos para esconder rugas e cabelos brancos como se fossem estigmas. Acrescente-se a isso, ainda, a hostilidade do espaço urbano e do transporte público, em cujos ônibus o idoso sobe com grandes dificuldades, e a 
O idoso na contemporaneidade: a necessidade de se educar a sociedade...

impaciência dos motoristas mais novos com a lentidão do idoso quando este ainda dirige (Whitaker, 2007).

O leitor atento à leitura do espaço urbano acrescentará ainda outros tópicos a essa lista de horrores e saberá, com certeza, que não é fácil manter a autoestima, principalmente para os idosos mais pobres, diante de tanta desvalia.

Muito se poderia dizer ainda sobre essa desvalia. E também sobre o lado positivo do processo... E sabemos que ele existe. ${ }^{2}$ Mas o alvo deste artigo é outro: refere-se à educação formal e se relaciona com tarefas a serem enfrentadas pela escola.

\section{O que pode a escola fazer para mudanças de atitude em relação} ao idoso?

Entre um grande elenco de preconceitos contra os idosos, o mais disseminado é aquele que os apresenta como desmemoriados. No entanto, paradoxalmente, os idosos têm mais memória do que os jovens, e por uma razão muito simples: viveram mais e, portanto, armazenaram mais fatos e acontecimentos em seus escaninhos mentais, cujas lembranças eles cultivam nostalgicamente e as expressam de boa vontade, quando convidados a falar.

Enquanto os jovens estão voltados para o futuro, os idosos contemplam o passado e fazem um constante balanço daquilo que viveram, presenciaram, testemunharam. Caberia à escola aproveitar esse manancial de recordações que ajudam a reconstruir a história de todos nós, criando programas de coleta de histórias de vida para a formação de arquivos. Estes seriam fontes orais para pesquisas de todos os tipos. $\mathrm{O}$ uso de tais fontes tem duplo benefício: por um lado, enriquece o capital cultural ${ }^{3}$ dos alunos entrevistadores e, por outro lado, faz crescer a autoestima do entrevistado.

Quando se pede a um idoso que fale sobre o passado, seus olhos brilham e a torrente de memórias que é capaz de mobilizar é espantosa. Pesquisas de história oral na região de Araraquara demonstraram a riqueza de informaçóes de que é capaz o idoso, mesmo quando em idade avançada e aparentemente lento em seus discursos (Whitaker, 2004). Idosos de diferentes classes sociais desvelam aspectos importantes do passado que se deve contrapor ao discurso oficial 
e ao documento histórico, muitas vezes comprometido com a dominação, quando não com a opressão.

A pesquisa histórica científica já realiza essa valorização da memória do idoso e os experimentos com história de vida (von Simson, 1988) compõem hoje importante acervo de descobertas fundamentais para compreensão histórica e das subjetividades (Whitaker \& Veloso, 2005).

O Estatuto do Idoso trouxe importante contribuição para a recuperação do prestígio e da dignidade desse grupo. Programas especiais têm sido elaborados para seu atendimento, em termos de saúde psicológica e mental (CNBB, 2002). No entanto, o idoso continua sendo desrespeitado na cena urbana, onde os espaços não são adequados ao seu andar lento e calculado; nas filas dos bancos, cujos lucros fabulosos nunca se transformaram em conforto para seus usuários; no sistema de saúde, cujas "liturgias" burocráticas nem sempre são adaptadas às suas necessidades; no sistema de promoção social, cujos funcionários não compreendem que direitos humanos são inalienáveis e que, portanto, conceder benefícios estabelecidos como direitos não significa tratar o idoso pobre como se estivesse pedindo esmola.

Se o artigo $3^{\circ}$ do Estatuto do Idoso estabelece como "obrigação da família, da comunidade e do Poder Público, assegurar” - entre muitas coisas - "dignidade" ao idoso, é preciso trabalhar para destruir, de uma vez por todas, o discurso que desvaloriza o envelhecimento e caracteriza o idoso como fardo a ser carregado pelos "futuros idosos". ${ }^{4}$

Afinal, se aldeias tribais e tribos indígenas marcadas pela pobreza material conseguem sustentar seus idosos com fartura de alimentos e homenagens e até, em alguns casos, atribuindo-lhes majestade, por que uma sociedade rica e afluente, cujos bilhões giram pelas bolsas de valores ao redor do mundo, lamenta constantemente o preço das aposentadorias e pensões dos seus idosos? Que sociedade é essa que descarta as doçuras da relação entre avós e netos e não contabiliza o papel essencial desempenhado pelos mais velhos em relação às crianças?

Ah! Se fosse possível elaborar políticas para a velhice, consultando as crianças, acho que essa quadra da existência seria menos triste. Os idosos das camadas exploradas da sociedade jamais sofreriam a falta de conforto, de remédio, de frutas, que caracteriza suas vidas. (Whitaker, 2007, p. 26) 
O idoso na contemporaneidade: a necessidade de se educar a sociedade...

Reivindicar um novo e diferente olhar sobre os idosos não significa a volta a um passado idílico que jamais existiu (afinal, o poder dos mais velhos podia ser, e era muitas vezes, despótico). Significa, sim, valorizar o ser humano na sua integridade. E, para que tal integridade se realize, é preciso, para cada pessoa, estar no mundo o tempo necessário para completar sua identidade. Quando somos jovens, estamos em processo de construção permanente da nossa identidade. O idoso revê posições, reformula atitudes, repara seus erros. Está em constante trabalho da memória. Mas, para realizá-lo, precisa de apoio, segurança, saúde e uma boa aposentadoria. Conforme assinalam Rios e Pontes (2006, p. 78), na velhice, as energias se direcionam para o mundo interior, o que "responde à necessidade de dar um sentido à vida, a seus processos, acontecimentos e escolhas feitas. A velhice é a fase da introspecção, do não-fazer, mas do estar e do ser. É a fase da realização plena do projeto da alma para aquela vida”.

Professores de crianças e adolescentes, em geral, têm receios de trabalhar com o Estatuto da Criança e do Adolescente (Rigobelo, 2010) - aliás, um diploma legal rodeado de preconceitos que atravessam todas as classes sociais. As marcas da escravidão, acentuadas por desigualdades sociais profundas, dificultam para o brasileiro, em geral, a compreensão do que sejam os direitos humanos, respeito à vida, solidariedade com os grupos vulneráveis. Está na hora da educação escolar trabalhar no sentido de formar novas atitudes, novos paradigmas para uma sociedade menos competitiva e mais sensível ao sofrimento.

Vivemos numa sociedade cheia de medos: medo do desemprego, medo de assaltos, medo do futuro... Mas idosos não oferecem perigo, apenas despertam ternura, oferecem sabedoria, confiam em suas memórias. É possível, então, que professores de crianças e adolescentes penetrem mais facilmente na complexa área dos direitos humanos, lendo o Estatuto do Idoso e colocando seus alunos em contato com a riqueza histórica representada pela memória dos idosos.

Recebido em abril de 2010 e aprovado em agosto de 2010.

\section{Notas}

1. Este processo resumido pode ser compreendido com mais detalhes no Capítulo "De como os idosos perderam o poder", em Whitaker (2007). 
2. Ao leitor interessado também no lado positivo do envelhecimento, aconselha-se Whitaker (2007). Para o leitor ainda mais interessado sobre o tema, há hoje uma vasta bibliografia sobre gerontologia. Ver, por exemplo, a coletânea organizada em dois volumes por Corte, Mercadante e Arcuri (2006).

3. Para o conceito de capital cultural, ver Bourdieu e Passeron (1975).

4. No livro Envelhecimento e poder, o alvo das mensagens é o "futuro idoso", ou seja, todos aqueles que esperam viver suficientemente para tornar-se idoso (Whitaker, 2007).

\section{Referências}

BOURDIEU, P.; PASSERON, J.C. A reprodução. Rio de Janeiro: Francisco Alves, 1975.

BRASIL. Lei n. 10.741, de $1^{\circ}$ de setembro de 2003. Dispóe sobre o Estatuto do Idoso e dá outras providências. São Paulo: Sugestões Literárias, 2003.

CONFERENCIA NACIONAL DOS BISPOS DO BRASIL (CNBB). Fraternidade e pessoas idosas. São Paulo: Salesiana, 2002. (Texto-base da Campanha da Fraternidade em 2003).

CORTE, B.; MERCADANTE, E.F.; ARCURI, I.G. Envelhecimento e velhice: um guia para a vida. São Paulo: Vetor, 2006. (Gerontologia, v. 1-2).

RIGOBELO, F.B.A. Direito educacional: em busca de uma educação refletora dos princípios, diretrizes e valores contidos no Estatuto da Criança e do Adolescente. 2010. Dissertação (Mestrado em Educação Escolar) - Faculdade de Ciências e Letras, Universidade Estadual Paulista, Araraquara.

RIOS, A.M.G.; PONTES, M.I.M. Envelhecimento da mulher: modelos na natureza. In: Corte, B.; Mercadante, E.F.; Arcuri, I.G. Envelhecimento e velhice: um guia para a vida. São Paulo: Vetor, 2006. (Gerontologia, v. 2).

VON SIMSON, O.R.M. Experimentos com histórias de vida: ItáliaBrasil. São Paulo: Vértice, 1988.

WHITAKER, D.C.A. Araraquara, histórias não reveladas. Presidente Venceslau: Letras à Margem, 2004. 
O idoso na contemporaneidade: a necessidade de se educar a sociedade...

WHITAKER, D.C.A. Envelhecimento e poder. Campinas: Alínea, 2007.

WHITAKER, D.C.A.; VELOSO, T.M.G. Oralidade e subjetividade: os meandros infinitos da memória. João Pessoa: FFPB, 2005. 